\title{
Specific inhalation challenge in the diagnosis of occupational asthma: consensus statement
}

\author{
Olivier Vandenplas ${ }^{1}$, Hille Suojalehto ${ }^{2,17}$, Tor B. Aasen ${ }^{3}$, Xaver Baur ${ }^{4}$, \\ P. Sherwood Burge ${ }^{5}$, Frederic de Blay ${ }^{6}$, David Fishwick ${ }^{7,8}$, Jennifer Hoyle ${ }^{8}$, \\ Piero Maestrelli9, Xavier Muñoz ${ }^{10,11}$, Gianna Moscato ${ }^{12}$, Joaquin Sastre ${ }^{11,13}$, \\ Torben Sigsgaard ${ }^{14}$, Katri Suuronen ${ }^{2}$, Jolanta Walusiak-Skorupa ${ }^{15}$, \\ Paul Cullinan ${ }^{16,17}$ and the ERS Task Force on Specific Inhalation \\ Challenges with Occupational Agents
}

\begin{abstract}
Affiliations: 'Dept of Chest Medicine, Mont-Godinne Hospital, Université Catholique de Louvain, Yvoir, Belgium. ${ }^{2}$ Occupational Medicine Team, Finnish Institute of Occupational Health, Helsinki, Finland. ${ }^{3}$ Dept of Occupational Medicine, Haukeland University Hospital, Bergen, Norway. ${ }^{4}$ Institute for Occupational Medicine, Charité University, Berlin, Germany. ${ }^{5}$ Dept of Respiratory Medicine, Heart of England NHS Foundation Trust, Birmingham, ${ }^{7}$ Dept of Respiratory Medicine, Royal Hallamshire Hospital, Sheffield, ${ }^{8}$ Dept of Respiratory Medicine, North Manchester General Hospital, Manchester, and ${ }^{16}$ Dept of Occupational and Environmental Medicine, Imperial College, National Heart and Lung Institute, London, UK. ' Division of Asthma and Allergy, Dept of Chest Diseases, University Hospital of Strasbourg, Fédération de Médecine translationnelle, Strasbourg University, Strasbourg, France. ${ }^{9}$ Dept of Cardiologic, Thoracic and Vascular Sciences, University of Padova, Padova, and ${ }^{12}$ Dept of Public Health, Experimental and Forensic Medicine of the University of Pavia, Pavia, Italy. ${ }^{10}$ Pulmonology Dept, Hospital Vall d'Hebron, Barcelona, ${ }^{11} \mathrm{CIBER}$ de Enfermedades Respiratorias (CIBERES), Madrid, and ${ }^{13}$ Allergy Dept, Fundacion Jimenez Diaz-Capio, Madrid, Spain. ${ }^{14}$ Dept of Public Health, Section of Environment, Occupation and Health, Aarhus University, Aarhus, Denmark. ${ }^{15}$ Dept of Occupational Diseases, Nofer Institute of Occupational Medicine, Łodz, Poland. ${ }^{17} \mathrm{H}$. Suojalehto and P. Cullinan are Task Force co-chairs.
\end{abstract}

Correspondence: H. Suojalehto, Occupational Medicine Team, Finnish Institute of Occupational Health, Topeliuksenkatu 41 a A, 00250 Helsinki, Finland. E-mail: hille.suojalehtodttl.fi

ABSTRACT This consensus statement provides practical recommendations for specific inhalation challenge (SIC) in the diagnosis of occupational asthma. They are derived from a systematic literature search, a census of active European centres, a Delphi conference and expert consensus. This article details each step of a SIC, including safety requirements, techniques for delivering agents, and methods for assessing and interpreting bronchial responses. The limitations of the procedure are also discussed.

Testing should only be carried out in hospitals where physicians and healthcare professionals have appropriate expertise. Tests should always include a control challenge, a gradual increase of exposure to the suspected agent, and close monitoring of the patient during the challenge and for at least $6 \mathrm{~h}$ afterwards. In expert centres, excessive reactions provoked by SIC are rare.

A positive response is defined by a fall in forced expiratory volume in $1 \mathrm{~s} \geqslant 15 \%$ from baseline. Equivocal reactions can sometimes be clarified by finding changes in nonspecific bronchial responsiveness, sputum eosinophils or exhaled nitric oxide. The sensitivity and specificity of SIC are high but not easily quantified, as the method is usually used as the reference standard for the diagnosis of occupational asthma.

@ERSpublications

ERS Task Force: a statement on specific inhalation challenges in the diagnosis of occupational asthma http://ow.ly/tCvFG 


\section{Introduction}

In this context, specific inhalation challenge (SIC) testing is the controlled exposure of a patient, under laboratory conditions, to an agent encountered in their workplace. In this article we are concerned with the use of SIC to identify immunologically mediated (or sensitiser-induced) occupational asthma in patients with a history of work-related symptoms [1-4]. A similar approach is used in the evaluation of hypersensitivity pneumonitis, but this is not discussed below. Common synonyms for SIC include specific "bronchial provocation testing" and "occupational-type challenge tests".

Although there are earlier, sporadic reports of its use, the procedure for SIC with occupational agents was formally developed in the early 1970s by PEPYs et al. [5], and initially performed in a corridor of the Royal Brompton Hospital (London, UK). In the intervening 40 years the practice has spread and become more sophisticated. In many centres, primarily in Canada and mainland Europe, SIC is regarded as a "first-line" procedure for diagnosing asthma arising from exposure to a respiratory sensitising agent in the workplace. In other centres it is reserved for cases where alternative methods have failed to identify, with sufficient accuracy, a specific causal exposure. SIC remains the best method of recognising the human sensitising potential of new agents, particularly chemical agents, encountered by persons in their work.

In 2011, the European Respiratory Society (ERS) formed a Task Force on SIC with occupational agents, comprising 15 specialist respiratory physicians from 10 European countries. Its principal aim was to issue guidance on the indications, methodology, interpretation and drawbacks of SIC. From the start, we recognised that several review articles [5-10], textbooks [11] and guidelines [12, 13] had covered similar ground but none of them were comprehensive and many were very dated. We did not aim to formulate a single, standardised approach to the use of SIC, recognising that there are important historical, jurisdictional and cultural determinants of its use that cannot, and need not, be included under a guise of "harmony".

We suggest that the information contained in this article will be of interest to those: 1) currently using SIC in the assessment of occupational asthma in Europe and elsewhere; 2) who are concerned with the risk assessment of (chemical) agents used in the workplace, particularly new such agents; and 3) planning to introduce SIC to their clinical practice.

This latter audience is, we believe, especially important. Although SIC is still acknowledged as the "reference standard" for demonstrating the causal relationship between exposure to an occupational agent and asthma $[1,2,4,14]$, recent information indicates that it is underused in the diagnostic evaluation of work-related asthma [15-19].

\section{Task Force methodology}

We undertook a variety of approaches to produce this guidance.

First, we performed a systematic bibliographic search through the library services at the Finnish Institute of Occupational Health, Helsinki, Finland (Appendix A in the online supplementary material). The retrieved abstracts were carefully explored by two Task Force members (P. Cullinan and H. Suojalehto) to identify relevant information on the performance of SIC with occupational agents. In addition, the reference lists of relevant articles and previous reviews were screened to identify any additional publications. The results of this systematic search were made available to all members of the Task Force.

Secondly, using a structured questionnaire, we surveyed the current practice of SIC with occupational agents in European centres among the members of the Occupational and Environmental Group of the ERS. A summary of this survey is published elsewhere [19].

Thirdly, we completed a two-stage Delphi exercise that aimed to judge the consistency of the Task Force member's views. The findings from this and the survey mentioned above were used in the preparation of the guidance.

Finally, we held four face-to-face meetings with the Task Force members between 2011 and 2013. Through these we prepared a list of "statements" pertaining to each step of SIC and considered the available evidence for each. A final consensus was reached through discussion.

The recommendations in this document were based on published evidence when available or on the results of the survey and Delphi process when it was not.

This article has supplementary material available from www.erj.ersjournals.com

Received: Oct 162013 | Accepted after revision: Jan 262014 | First published online: Mar 62014

Conflict of interest: Disclosures can be found alongside the online version of this article at www.erj.ersjournals.com 
In addition to this guidance, we developed a "handbook" of practical methods for performing SIC with individual workplace agents, under the direction of K. Suuronen (Finnish Institute of Occupational Health). The handbook contains a summary of the methods used by 22 European centres and is available in the online supplementary material.

\section{Rationale and indications for performing specific inhalation challenges}

SIC aims to investigate empirically the specific reactivity of the airways to occupational agents (of either high- or low-molecular-weight (HMW and LMW, respectively)) in workers who have symptoms of workrelated asthma. The rationale for performing SIC is, therefore, to improve the diagnosis of work-related asthma. There is accumulating evidence that workplace exposures contribute substantially to the global burden of asthma, accounting for $\sim 15 \%$ of all adult-onset disease [20, 21]. Up to $20 \%$ of adults with asthma report provocation of their symptoms in the workplace [22], although only a minority have immunologically or sensitiser-induced occupational asthma [23]. A timely and accurate diagnosis of occupational asthma is a key element in advising appropriate treatment or other interventions and minimising the adverse health and socioeconomic outcomes of the disease $[4,24,25]$. The accurate identification of an index case of occupational asthma and its aetiology is also important for implementing primary preventive measures for other exposed workers.

The evidence-based guidelines issued by the British Occupational Health Research Foundation acknowledged that: "A carefully controlled SIC comes closest to a gold standard test for some agents causing OA [occupational asthma]", but "a negative test in a worker with otherwise good evidence of OA is not sufficient to exclude the diagnosis" [1]. The systematic review conducted by the Agency for Healthcare Research and Quality [14] concluded that "as yet there is no definitive diagnostic test for OA" and considered SIC to be a "reference standard" rather than the "gold standard". The expert-based consensus statement issued by the American College of Chest Physicians [2] recommended that: "In individuals with suspected sensitizer-induced OA, conducting SIC (where available) is suggested when the diagnosis or causative agent remains equivocal".

This Task Force agreed that the broad categories of indications for performing SIC with an occupational agent include: 1) confirmation of the diagnosis of occupational asthma when other objective methods are not feasible, are less efficient or have failed to provide definitive results; 2) identification of the cause of occupational asthma when other objective methods are not feasible, are less efficient or have failed to provide definitive results; 3) the identification of a new (not formerly described) specific cause of occupational asthma; and 4) research into the mechanisms of work-related asthma.

The place of SIC in the diagnostic evaluation of a patient with suspected occupational asthma is summarised in figure 1. Within these indications, the use of SIC is influenced by the final purpose of the diagnostic evaluation. For instance, the desired level of diagnostic accuracy may be different for clinical, research, compensatory or occupational health surveillance purposes. The use of SIC should also take into account patient important and societal outcomes. All of these may vary between jurisdictions and different countries.

\section{Methodology of specific inhalation challenges}

Key messages for performing reliable and safe SICs with occupational agents are summarised in table 1.

\section{General safety requirements}

SIC should only be carried out in hospital-based specialised centres [13]. Patients may be admitted to hospital for the duration of the SIC; where they are not, facilities for their management in the case of excessive reactions, including those in the late-phase, must be readily available. SIC should be conducted by trained personnel who have received precise training in the challenge protocol including when and how to stop further exposure, and in emergency procedures $[13,26]$. SIC should be closely supervised by physicians who have expertise in the field and are readily available to manage acute asthmatic or anaphylactic reactions according to current guidelines [27, 28].

SIC should be performed in enclosed challenge rooms equipped with an adequate exhaust ventilation system or using closed-circuit devices [29-32], in order to prevent inadvertent exposure of the technicians and the tested patient after discontinuation of the challenge. Some patients with occupational asthma are extremely sensitive to very small quantities of the agent to which they are sensitised. During SIC, patients should wear protective overalls, caps, eye protection, shoes and non-latex gloves to avoid, as far as possible, direct skin exposure to the tested agent.

The patient should receive detailed information on the purpose and procedures of the tests and on their potential adverse effects. Females of child-bearing age should be clearly informed that SIC is not advised 


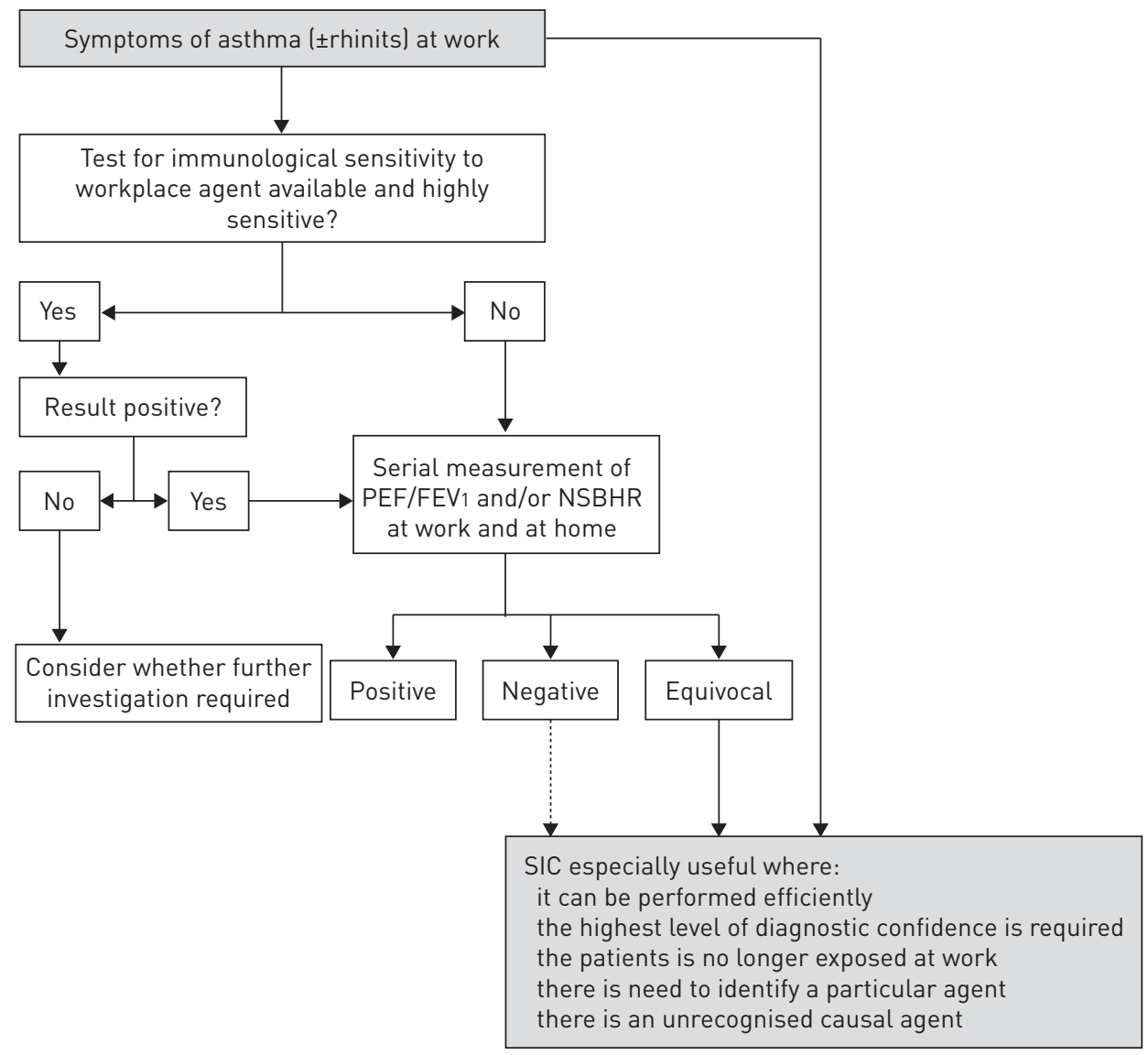

FIGURE 1 The place of specific inhalation challenge (SIC) in the diagnosis of occupational asthma. In some centres it is the first-choice technique, in others it is used selectively in the context of other diagnostic approaches (white boxes). PEF: peak expiratory flow; FEV1: forced expiratory volume in $1 \mathrm{~s}$; NSBHR: nonspecific bronchial hyperresponsiveness.

during pregnancy. There is a consensus that subjects undergoing an SIC procedure should be asked to sign a statement of informed consent.

\section{Contraindications}

It is generally agreed that SIC is contraindicated in patients with severe airway obstruction. However, the threshold value of forced expiratory volume in $1 \mathrm{~s}$ (FEV1) below which a SIC should not be performed remains controversial, mainly because of a lack of evidence-based information. For inhalation challenges with common inhalant allergens, the European Academy of Allergology and Clinical Immunology

\section{TABLE 1 Key messages for performing and interpreting specific inhalation challenge (SIC) with occupational agents}

General safety requirements, contraindications and precautions should be strictly applied in order to minimise the risk of severe adverse events The duration or concentration of exposure to occupational agents should only be gradually increased under close monitoring of functional parameters

A control challenge test with a 6-8 h period of spirometric monitoring on a separate day is required for the interpretation of the SIC results

Changes in FEV1 should be the primary physiological outcome measure, but other functional indices (i.e. airway resistance/conductance) may be useful in subjects who are not able to complete reproducible expiratory manoeuvres

NSBHR should be measured at least before the SIC and at the end of a negative SIC procedure. A significant increase in post-challenge NSBHR provides further evidence for a positive response when changes in FEV1 are indeterminate and indicates that additional challenges are necessary before excluding a diagnosis of occupational asthma

Sputum eosinophils and FeNO may help interpret equivocal tests and indicate the need for longer SIC exposures to reduce the risk of false-negative results

FEV1: forced expiratory volume in $1 \mathrm{~s}$; NSBHR: nonspecific bronchial hyperresponsiveness; FeNO: exhaled nitric oxide fraction. 
Subcommittee on provocation tests with allergens recommended that baseline FEV1 should be $\geqslant 70 \%$ predicted [33]. The Delphi exercise undertaken by members of the Task Force concluded that SIC with occupational agents can be performed safely and validly in subjects with an FEV1 $>60 \%$ predicted. SICs should only be performed in subjects with stable asthma as ascertained by FEV1 monitoring on a control day.

Other (absolute or relative) contraindications to SIC include: any recent or unstable cardiovascular disease, uncontrolled epilepsy, pregnancy, recent ( $<4$ weeks) respiratory tract infection, and a patient's inability to understand the procedures $[13,26,33]$.

\section{Precautions}

Medications

Prior to SIC, inhaled bronchodilators, theophyllines, leukotriene receptor antagonists, cromoglycate and antihistamines should be withdrawn according to their durations of action. Preferably, inhaled corticosteroids should also be stopped. Previous studies indicate that inhaled and oral corticosteroids significantly attenuate, in a dose-dependent manner, the bronchial response to allergens, especially the late phase component and the associated increase in nonspecific bronchial hyperresponsiveness (NSBHR), but that they do not completely inhibit the bronchial response [34-48]. The protective effect of inhaled steroids against allergen-induced early responses, airway eosinophilia and increases in NSBHR is partially or completely lost as early as $12 \mathrm{~h}$ after discontinuation of therapy [48]. This Task Force recommends withholding corticosteroid treatment (inhaled and/or oral) for at least $72 \mathrm{~h}$ before the test, whenever feasible. Nevertheless, it has been suggested that their total daily dose can be administered in the evening at the end of each challenge day, if required to maintain asthma control. Such an approach should be considered, particularly when SIC is carried out over prolonged periods, in order to minimise the risk of asthma worsening. Patients should be asked to refrain from smoking during the period of SIC, although an impact of tobacco smoke on specific bronchial reactivity to occupational agents has not been clearly identified [49].

Removal of patients from their workplace exposure for several days before SIC is not mandatory, and may lead to adverse employment consequences for them. Nevertheless, avoidance of exposure before testing should be considered when asthma is not functionally stable. Removal may also be useful for the assessment of the variability in FEV1 over several days that is required for the statistical method of evaluation of asthmatic reactions [50].

\section{Patient surveillance}

Patients should be monitored in the laboratory for 6-8 h after the end of the control and active challenge exposures. Thereafter, they should, while awake, make self-measurements of FEV1 or peak expiratory flow (PEF) using portable instruments until the following morning in order to detect relapsing bronchoconstriction. Asthmatic reactions in patients who failed to show significant changes in FEV 1 during the 6-8 h follow-up period in the laboratory seem to be rare (e.g. three out of 335 SICs) (unpublished data). Changes in airway calibre that have not been documented through supervised spirometry measurements should lead to a repeat of the challenge on a subsequent day. The subjects should be allowed to leave the laboratory at the end of the follow-up period provided that their FEV1 is within $10 \%$ of its baseline value, either spontaneously or after administration of an inhaled bronchodilator. If they are not to be kept in hospital overnight, they should receive contact information and be carefully instructed on how they should treat relapsing bronchoconstriction based on self-recorded FEV1/PEF values. As a result, SIC can be performed on an outpatient basis, but patients who develop severe/persistent asthmatic reactions should be hospitalised for overnight surveillance. Patients who develop marked late reactions should be treated with inhaled corticosteroids for a few days after the challenge in order to minimise the risk of transient worsening of asthma symptoms [33].

\section{Procedure}

A flowchart summarising the main steps in performing SIC with an occupational agent is presented in figure 2.

\section{Control day}

Prior to the challenge with the suspected occupational agent, a "control" day should be performed by exposing the patient to a control substance, usually for 30-60 min. Functional outcome parameters should be monitored for 6-8 h afterwards, as with the follow-up period after challenge with the suspected "active" agent $[5,13,33]$. The purpose of this control day is two-fold. 1) To verify the functional stability that is crucial for the correct interpretation of changes in FEV1 after exposure to the suspected occupational agent. When the changes in FEV1 after exposure on the "control" day exceed 10\% of the baseline value the subject 


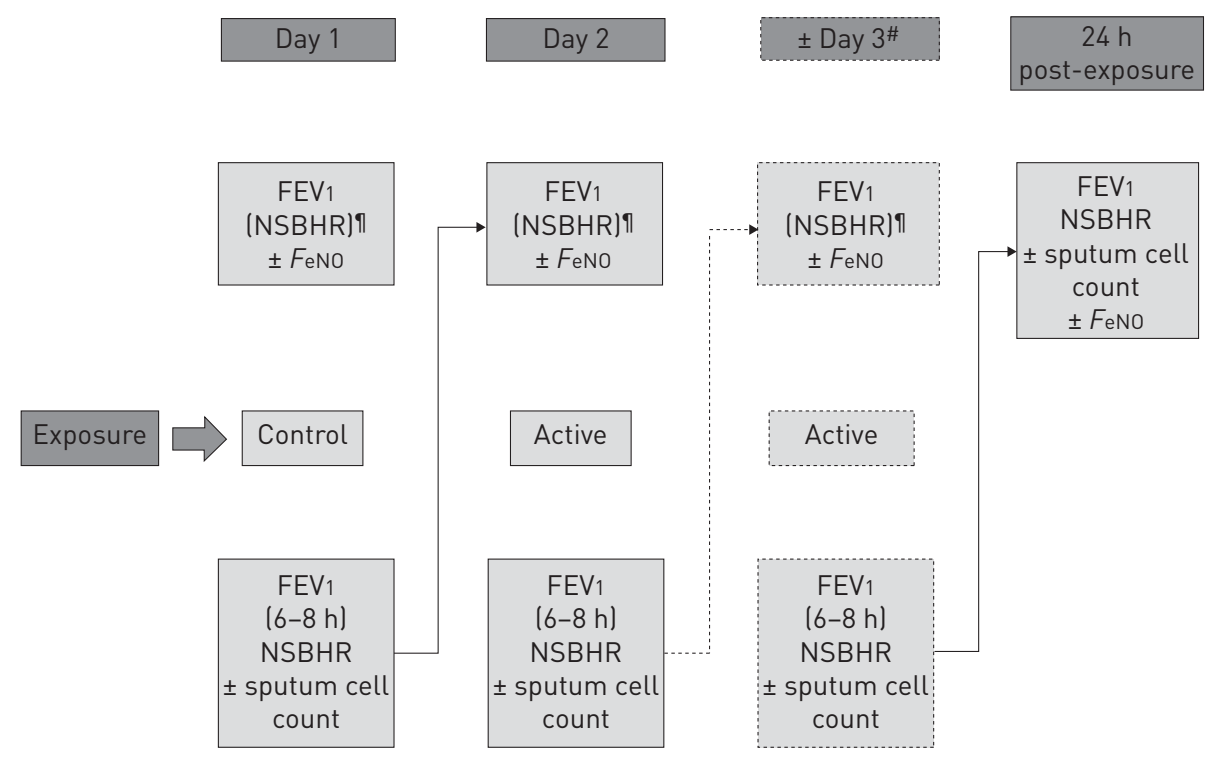

FIGURE 2 Schematic flowchart for performing specific inhalation challenge with an occupational agent. The timing of some measurements varies between centres. FEV1: forced expiratory volume in $1 \mathrm{~s}$; NSBHR: nonspecific bronchial hyperresponsiveness; FeNO: exhaled nitric oxide fraction. " : proceed to additional active challenge(s) when the changes in FEV1 on day 2 are equivocal or negative and challenge with a higher dose is considered appropriate, or when there is a significant increase in sputum eosinophils or in FeNO post-day 2 challenge. ${ }^{\circ}$ : NSBHR can be measured in the morning before the control and active challenge exposures provided that no inhaled bronchodilator is administered.

should not be challenged with an occupational agent until their asthma has been stabilised through the use of anti-asthma medication or removal from suspected offending exposure. 2) To provide a point of comparison for any reactions to the active test agent and to identify nonspecific irritant reactions to the control agent which would suggest that any response to an occupational agent may also be irritant and does not meet the definition of specific bronchial hyperreactivity [51].

The "control" substance is usually selected with reference to the nature of the occupational agent suspected of causing occupational asthma. The control substance may be equally irritant and/or may have the same physical appearance as the tested occupational agent. The most commonly used control substances include: lactose powder for SIC with agents in powder form (flour, drugs and persulfate); pine dust for SIC with wood dusts; vinyl gloves for SIC with latex gloves; and solvents for polyurethane products and other resins.

In order to maintain objectivity, it is good practice not to inform the patient whether they are undergoing "control" or "active" exposure during SIC, although effective "blinding" of patients is not always possible.

Methods for delivering occupational agents

The basic principle of SIC is to deliver the suspected occupational agent in the same conditions as those that prevail in the workplace in terms of its physical characteristics (i.e. gas, fumes, liquid or particles aerosols) and its chemical form (e.g. monomer versus polymer), preferably on the basis of a detailed workplace exposure assessment [5]. The bronchial response to an occupational agent may vary according to its physicochemical characteristics [52-54]. Nebulising saline solutions of water-soluble HMW agents has limitations since standardised solutions of occupational agents are lacking (except for latex), and some relevant allergens may not be water soluble $[55,56]$.

Thus, exposure to occupational agents in SIC should be produced in various ways, depending on the nature of the agent suspected of causing occupational asthma. A practical handbook describing the methods that are currently used for generating the most commonly tested agents has been prepared by a Technical Group of the Task Force and is available in the online supplement. The methodology, limitations and indications of supervised workplace challenges are addressed in Appendix B in the online supplement.

\section{Concentration of exposure}

The concentration of the occupational agent in the air during SIC should be based on the estimated level in the workplace but should not exceed relevant occupational exposure limits (OEL). Ideally, the concentration and, when relevant, particle size should be continuously monitored during SIC and the concentration kept below the OEL in order to avoid irritant responses and/or severe asthmatic reactions. In 
practice, appropriate techniques for measuring the wide variety of agents causing occupational asthma are seldom available. However, provision should be made for the online measurement of chemical agents with a high potential for inducing severe reactions, especially diisocyanates.

\section{Duration of exposure}

The duration of exposure to the suspected occupational agent should only be increased very gradually (e.g. $10 \mathrm{~s}, 1 \mathrm{~min}, 5 \mathrm{~min}, 10 \mathrm{~min}, 15 \mathrm{~min}, 30 \mathrm{~min}$ and $60 \mathrm{~min}$ ) and especially when the subject reports a history of severe acute reactions at work or has marked NSBHR (e.g. histamine/methacholine provocation concentration causing a $20 \%$ fall in FEV1 $\left.\left(\mathrm{PC}_{20}\right) \leqslant 0.25 \mathrm{mg} \cdot \mathrm{mL}^{-1}\right)$ and when the challenge involves a LMW agent [57] or one with a high allergenic potential (e.g. enzymes). For HMW agents, the duration of exposure can be increased progressively on the same day until an immediate reaction occurs or until the maximum duration of exposure is reached. For LMW agents that are more likely to cause isolated late and atypical reactions [58], the duration of exposure should preferably be increased from one day to the next with, for instance, a cumulative exposure limited to $<30 \mathrm{~min}$ on the first challenge day [11, 13, 57].

Since dose (concentration $\times$ time) is the main determinant of the bronchial response [59, 60], an alternative approach is to increase the concentration of the agent, rather than the duration of exposure. Determining the initial concentration/dilution of the delivered agent can be guided by the level of specific IgE sensitisation to this agent. Thus, studies have documented that the concentration of common allergens required to induce a $20 \%$ fall in FEV1 can be derived from the baseline degree of NSBHR to histamine/ methacholine and the level of IgE sensitisation to the allergen, [61, 62]. However, these relationships are still under debated [63] and, with the exception of flour [64], have never been established for occupational sensitisers. It is recommended that the starting concentration of nebulised allergen be set at the lowest concentration producing a threshold response on skin-prick testing (the "skin end-point" concentration) $[5,65]$ or at three doubling concentrations below the predicted concentration derived from the formula $[33,65]$. The concentration of agents administered in powder form can also be progressively increased by using progressive dilutions in lactose powder (e.g. from 1/1000 to 1/10); the starting concentration is usually a dilution 10 times lower than that inducing a positive skin-test response to the saline dilution. Such strategies are particularly important in enhancing the safety of SIC with previously unknown sensitising agents [66, 67].

It remains unclear how long a subject should be exposed to the suspected agent before the test can be considered negative. A retrospective review of 335 positive SICs showed that the threshold duration of challenge exposure required to induce an asthmatic reaction was $>2 \mathrm{~h}$ in $25 \%$ of the subjects [49]. A multivariate linear regression analysis showed that a longer duration of exposure was associated with challenge exposure to LMW agents, a lower level of baseline NSBHR, increasing age, and a shorter duration of asthma symptoms at work. Other individual characteristics that could affect specific bronchial reactivity to occupational agents have not been thoroughly explored.

When SIC is performed sequentially to more than one occupational agent, exposure to the second or subsequent agent should not be started before a patient's FEV1 and NSBHR have returned to pre-SIC levels.

\section{Assessment of bronchial response}

SIC aims to verify that exposure to a suspected occupational agent induces the characteristic features of asthma, i.e. airway obstruction, development or increase in NSBHR, and/or airway inflammation. A positive test is one from which it can reasonably be concluded that exposure actually caused the response, rather than the response being due to confounding factors.

\section{Airway obstruction}

The FEV1 remains the primary physiological outcome measure for assessing changes in airway calibre. This parameter is well standardised and reproducible $[68,69]$. No other functional parameters have been demonstrated to be superior to FEV1 in the evaluation of bronchial response to SIC. Peak expiratory flow shows reproducibility and sensitivity that are similar to FEV1 [70], but this test is more dependent on muscular effort and has no benefit over FEV1 for use during supervised measurements in hospital [71]. Measurements of airway resistance or conductance by body plethysmography $[65,72-74]$ and respiratory resistance by the forced oscillation technique [75] are not affected by inspiratory manoeuvres and are not effort-dependent, but they are less reproducible and require more expensive equipment. Nevertheless, these parameters may be useful in subjects who are not able to perform reproducible spirometric manoeuvres and may provide useful complementary evidence of a significant bronchial response during SICs that produce equivocal changes in FEV1 [76].

Parameters of airway obstruction should be measured after each incremental exposure to the occupational agent. When the FEV1 falls by $>10 \%$ from baseline, it should be re-assessed 10-20 min later, before 
re-exposing the subject [77]. After the end of a challenge any airway obstruction should be assessed at 10-15 min intervals during the first hour, and then every 30-60 min for the next 6-8 h. Assessment of FEV1 the next morning (i.e. $\sim 24 \mathrm{~h}$ after the end of challenge exposure) is helpful to disclose a "day-to-day" pattern of reactions [78].

\section{Nonspecific bronchial hyperresponsiveness}

The Delphi exercise of the Task Force concluded that any validated test to detect NSBHR (methacholine, histamine, adenosine monophosphate and mannitol) can be used in SIC [13, 26]. At a minimum, NSBHR should be measured at baseline and re-assessed after the SIC, especially when there have been no significant changes in airway calibre. A significant increase in post-challenge NSBHR to histamine or methacholine (i.e. more than two- to three-fold reduction in post-challenge PC20/provocation dose causing a $20 \%$ fall in FEV1 (PD20) values compared to baseline) $[73,79,80]$ means that the subject should be further challenged before excluding the diagnosis of occupational asthma. Among 50 subjects who failed to develop significant changes in FEV1 after a 2-h challenge exposure to occupational agents, 11 (22\%) showed a post-challenge increase in NSBHR, of whom nine (i.e. $18 \%$ of all negative responses) developed an asthmatic reaction on subsequent challenge(s) [79, 80].

\section{Airway inflammation}

Sputum eosinophils

Sputum eosinophil counts may be evaluated at baseline and after SIC that has resulted in no changes in FEV1. Recent prospective data indicate that an increase in sputum eosinophils is an early marker of specific bronchial reactivity to occupational agents and may help to identify subjects who will develop an asthmatic reaction after repeated challenge exposure [81]. A $>3 \%$ absolute increase in sputum eosinophils as compared to baseline after a 2 -h challenge yielded a sensitivity of $67 \%$ and a specificity of $97 \%$ in predicting the development of an asthmatic response on subsequent challenge(s) [81]. A post-challenge increase in sputum neutrophil count has also been documented [81, 82], especially after exposure to LMW agents [83, 84]. However, the interpretation of changes in sputum neutrophil counts has not yet been further validated.

\section{Exhaled nitric oxide}

Assessment of changes in exhaled nitric oxide fraction ( $F$ eNO) level during SIC may be useful in subjects who fail to provide suitable sputum samples $[85,86]$. There have been conflicting data on the changes in FeNO after SIC with occupational agents [87-95]. A significant increase in FeNO level was observed only $24 \mathrm{~h}$ after positive challenges, while there was a significant increase in sputum eosinophil at $7 \mathrm{~h}[92,96]$. Changes in FeNO were less discriminant than the changes in sputum eosinophils [96].

\section{Other outcome parameters}

Body temperature and measurement of the diffusing capacity of the lung for carbon monoxide can be measured during SIC when there is a clinical suspicion of hypersensitivity pneumonitis-like reaction [97-99].

Assessment of nasal response during SIC may be useful for confirming associated occupational rhinitis. The assessment of nasal symptoms is not always sufficient to document a nasal reaction; symptom scores should be combined with objective measurements, i.e. demonstration of a significant decrease in nasal patency and/ or evidence of nasal inflammation [100-103].

\section{Interpretation of specific inhalation challenge results}

\section{Airway obstruction}

A SIC is generally considered positive when there is a sustained (i.e. recorded on two consecutive assessments) fall in FEV1 of at least 15\% from pre-challenge value, provided that fluctuations in FEV1 are $<10 \%$ during a $6-8 \mathrm{~h}$ follow-up on a control day. This threshold value is arbitrary and a more rational approach would be to take into account the subject's variability in FEV1 when not exposed to the suspected agent. Such statistical methods are likely to be more sensitive than a fixed threshold value [50] but they require serial measurements of FEV1 on several (at least three) unexposed days in order to obtain an adequate estimate of the variance of the FEV1 [50, 104-106]. There is no consensus on the interpretation of PEF changes after SIC but their assessment should similarly take into consideration the natural ("unexposed") variability of a subject's measurements; this is likely to be higher than the variability in measurements of FEV1.

A decrease of $>50 \%$ in specific airway conductance from baseline (combined with a decline below $0.5 \mathrm{kPa} \cdot \mathrm{s}^{-1}$ ) or an increase in specific airway resistance of $>100 \%$ (exceeding the threshold value of $2 \mathrm{kPa} \cdot \mathrm{s}^{-1}$ ) are usually regarded as positive bronchial responses to allergens and occupational agents [65, 107]. 


\section{Nonspecific bronchial hyperresponsiveness}

When changes in FEV1 are indeterminate, a significant increase in post-challenge NSBHR provides further evidence for a positive response, although these changes are not constantly observed after asthmatic reactions due to sensitising agents [3]. It remains debatable whether an isolated (i.e. in the absence of $\geqslant 15 \%$ fall in $\mathrm{FEV} 1$ ) increase in post-challenge NSBHR to histamine/methacholine (i.e. more than two- to three-fold decrease in the PC20 or PD20 compared to baseline value) can be considered a positive SIC. Available data suggest that such changes have a high $(>90 \%)$ predictive value for the development of an asthmatic reaction on subsequent challenges and indicate the need for additional challenges before excluding a diagnosis of occupational asthma [79, 80].

\section{Airway inflammation}

In cases where the changes in FEV1 are equivocal, the following would support a positive SIC response: 1) a post-challenge increase in sputum eosinophils of $>3 \%$ compared to baseline value; or 2) an increase in FeNO $24 \mathrm{~h}$ after the challenge. Several threshold values for a significant increase in FeNO have been proposed: an increase of $>30-40 \%$ compared to pre-challenge value $[94,95]$ and an increase $>20 \%$ for baseline values over $50 \mathrm{ppb}$ or $>10 \mathrm{ppb}$ for values lower than $50 \mathrm{ppb}$ [108]. It remains uncertain whether a significant increase in post-challenge airway inflammation parameters can be considered a positive SIC result in the absence of significant changes in airway calibre; nevertheless, the absence of change in airway inflammation parameters cannot be used to support a negative SIC.

A diagnosis of occupational eosinophilic bronchitis should be considered when SIC results in increased sputum eosinophils without changes in FEV1 and the absence of NSBHR [109-115].

\section{Other parameters}

An increase in body temperature $>0.5^{\circ} \mathrm{C}$ during SIC showed a sensitivity of $100 \%$ and a specificity of $82 \%$ in the diagnosis of hypersensitivity pneumonitis [98]. Criteria for identifying hypersensitivity pneumonitis based on a combination of clinical and physiological parameters have also been proposed [97, 99].

\section{Patterns of asthmatic reactions}

SIC with occupational agents can induce typical and atypical patterns of asthmatic reactions $[5,58]$. Isolated late reactions and atypical reactions occur more frequently during SIC with LMW agents $[58,116,117]$. Isolated early responses have been more frequently documented in females, smokers, workers with a higher FEV1 \% predicted and lower level of NSBHR, and in those with longer asthma duration [117].

Typical patterns

The typical patters are as follows. 1) Immediate/early reaction: onset during exposure or a few minutes after the end of exposure and recovery over 1-2 h. 2) Late reactions: onset later than 2 h after exposure. 3) Dual/ biphasic reactions: a combination of immediate and late reactions.

\section{Atypical patterns}

The atypical patterns are as follows. 1) Prolonged immediate reaction: similar to immediate but slower recovery over several hours. 2) Progressive reaction: onset within minutes after the end of exposure with a progressive decline in FEV1 over the following hours. This may require repeated administration of inhaled bronchodilator and often oral corticosteroids. 3) Square-waved reaction: similar to a dual reaction but without recovery between the immediate and late components of the reaction.

\section{Limitations of specific inhalation challenges \\ False-negative results}

False negative SIC results may occur when the subject has not been challenged with the agent that actually caused their asthma at work or when the amount or form (particle size, temperature, etc.) of the relevant agent has been insufficient or inappropriate. This issue can be minimised by obtaining a careful occupational history and collecting detailed information on the compounds to which the patient is directly or indirectly exposed at the workplace. The history can be fruitfully supplemented by job analysis performed by industrial hygienists and measurements at the workplace whenever available.

False-negative results may also occur when the specific bronchial reactivity to the causal agent has decreased or has been lost after lengthy removal from exposure. Few studies have evaluated the outcome of specific bronchial reactivity after cessation of exposure to the sensitising agent [118-123]. LEMIÈRE et al. [122] found that only $7 \%$ of the subjects lost their specific bronchial responsiveness to the causal agent, although the duration of exposure required to elicit a positive SIC response significantly increased (3.4-fold on average) after removal from the offending exposure. Most studies, with one exception [118], found that there was no 
relationship between the changes in NSBHR and specific reactivity to occupational agents [119, 121-123]. These data indicate that false-negative SIC results, due to a decrease of the specific bronchial reactivity to the causal agent, can be markedly reduced by applying the following measures. 1) The duration of the challenge exposure should be sufficiently prolonged [49]. 2) The level of NSBHR [79] and/or sputum eosinophils [81] should be assessed after SICs that do not induce a significant fall in FEV1; significant post-challenge changes in these sensitive markers should lead to further challenge before excluding the diagnosis of occupational asthma.

When a SIC test in the laboratory is negative despite prolonged exposure and use of sensitive indices of bronchial response, but there is a high clinical suspicion of occupational asthma, the subject should be returned to work while monitoring FEV1 or PEF.

\section{False-positive results}

A false-positive reaction may theoretically result from a nonspecific irritant bronchoconstriction which does not fit the definition of occupational asthma due to specific bronchial hypersensitivity to an occupational agent $[1-3,124]$. Immediate bronchial responses to irritant stimuli cannot be easily distinguished from those caused by sensitising agents, since their temporal patterns are very similar. Such false-positive SIC results can be reduced by the following measures. 1) Exposure to a control substance may allow the identification of subjects who are likely to develop nonspecific reactions on subsequent challenge with occupational agents. 2) The occurrence of nonspecific reactions should theoretically be prevented by exposing the subjects to concentrations below the OEL. Most controlled experiments in asthmatic volunteers have failed to demonstrate a physiologically relevant effect of exposure to irritant substances at permissible levels [125-130], although some individuals developed minimal changes in airway calibre $[126,127]$. Some irritant substances, such as sulfur dioxide [131] and chlorine [132, 133], can induce a transient decrease in lung function in asthmatic subjects. However, maintaining the level of exposure below the OEL would imply monitoring the concentrations of a wide variety of compounds during SICs, which is generally not feasible. Devices that allow continuous concentration measurement and regulation of the products generated during SIC could be helpful in reducing nonspecific reactions [29-32].

\section{Adverse effects}

Excessive asthmatic responses

The experience of specialised centres indicates that SIC are associated with only minimal risk of inducing severe asthmatic reactions provided that safety requirements are stringently respected, risk factors are taken into account, exposures to occupational agents are only progressively increased, and bronchial responses are carefully monitored [19]. A recent review of 335 positive SICs performed in a single centre using realistic methods of exposure showed that $12 \%$ required repeated administration of an inhaled short-acting bronchodilator, while few $(3 \%, 95 \%$ CI 1-5\%) induced an asthmatic reaction that required additional oral or intravenous corticosteroids [57]. A multivariate analysis showed that the risk of a moderate or severe reaction was increased when the subjects were challenged with a LMW agent and when they were using an inhaled corticosteroid. Notably, the baseline level of NSBHR and a history of severe exacerbation at work were not predictive for the development of a severe reaction during the SICs.

\section{Exacerbation of asthma}

SICs have been reported to induce transient exacerbations of asthma with recurrent nocturnal symptoms [134], although this seems to be a rare occurrence in clinical practice. We recommend starting or increasing inhaled corticosteroids for a short period (e.g. 4-6 days) in subjects who develop marked late reactions in order to minimise the associated increase in inflammatory processes and NSBHR [33], although the evidence supporting this recommendation is currently lacking.

Fever and systemic symptoms

Fever and systemic flu-like symptoms may occur in about $5 \%$ of patients with a positive SIC [135]. Fever seems to occur more frequently among subjects who show a late or an atypical reaction and when a LMW agent is involved (e.g. diisocyanates and metals).

\section{Cutaneous and anaphylactic reactions}

Cutaneous and anaphylactic reactions have occasionally been reported during SICs [136-140]. Skin contact with occupational agents should be reduced as much as possible during SIC by using protective clothes or closed-circuit delivery systems. In a series of 335 positive SICs, an urticarial reaction was recorded in five (1.5\%) patients (unpublished data). Urticaria was localised to the face in four subjects, while there was only one case of extensive urticaria and hypotension caused by phthalic anhydride, which resolved after subcutaneous administration of adrenalin. 


\section{Cost of the procedure}

There are very few data on the relative cost-effectiveness of the various procedures that can be used to diagnose occupational asthma. Using Canadian and US cost estimates, KenNEDY et al. [141] found that the SIC, used as the gold standard with an assumed $100 \%$ accuracy, was the most expensive technique, but correctly diagnosed $28 \%$ more occupational asthma patients than the analysis of sputum cells collected at work and off work, and 48\% more patients than PEF monitoring. The costs resulting from an incorrect diagnosis of occupational asthma have never been evaluated, but are likely to outweigh the additional cost of the SIC procedure.

\section{Research needs}

The Task Force identified that the major research needed was the investigation and development of improved methods of distinguishing bronchial responses to irritant stimuli and sensitising agents.

\section{Conclusion}

Although SIC with occupational agents is regarded as the reference method for diagnosing occupational asthma, the test is probably underused and facilities for its performance are not widely available. The main objective of this Task Force was to harmonise occupational SIC testing in Europe and to provide guidance to physicians who wish to develop SIC testing in new centres. The guidance provides consensus statements on the essentials of practise and interpretation of SIC testing and practical recommendations on the minimum requirements for performing safe and reliable SIC tests in order to assist clinicians who wish to offer SIC tests in the diagnosis of work-related asthma.

\section{References}

1 Nicholson PJ, Cullinan P, Taylor AJ, et al. Evidence based guidelines for the prevention, identification, and management of occupational asthma. Occup Environ Med 2005; 62: 290-299.

2 Tarlo SM, Balmes J, Balkissoon R, et al. Diagnosis and management of work-related asthma: American College of Chest Physicians Consensus statement. Chest 2008; 134: Suppl. 3, 1S-41S.

3 Malo JL, Vandenplas O. Definitions and classification of work-related asthma. Immunol Allergy Clin North Am 2011; 31: 645-662.

4 Baur X, Sigsgaard T, Aasen TB, et al. Guidelines for the management of work-related asthma. Eur Respir J 2012; 39: 529-545.

5 Pepys J, Hutchcroft BJ. Bronchial provocation tests in etiologic diagnosis and analysis of asthma. Am Rev Respir Dis 1975; 112: 829-859.

6 Banks DE, Tarlo SM, Masri F, et al. Bronchoprovocation tests in the diagnosis of isocyanate-induced asthma. Chest 1996; 109: 1370-1379.

7 Vandenplas O, Malo JL. Inhalation challenges with agents causing occupational asthma. Eur Respir J 1997; 10: 2612-2629.

8 Tarlo SM. Laboratory challenge testing for occupational asthma. J Allergy Clin Immunol 2003; 111: 692-694.

9 Banks DE. Use of the specific challenge in the diagnosis of occupational asthma: a "gold standard" test or a test not used in current practice of occupational asthma? Curr Opin Allergy Clin Immunol 2003; 3: 101-107.

10 Mapp CE, Boschetto P, Maestrelli P, et al. Occupational asthma. Am J Respir Crit Care Med 2005; 172: 280-305.

11 Vandenplas O, Cartier A, Malo JL. Occupational challenge tests. In: Bernstein IL, Chan-Yeung M, Malo JL, et al, eds. Asthma in the Workplace. 3rd Edn. New York, Taylor and Francis, 2006; pp. 227-252.

12 Cartier A, Bernstein IL, Burge PS, et al. Guidelines for bronchoprovocation on the investigation of occupational asthma. Report of the Subcommittee on Bronchoprovocation for Occupational Asthma. J Allergy Clin Immunol 1989; 84: 823-829.

13 Sterk PJ, Fabbri LM, Quanjer PH, et al. Airway responsiveness. Standardized challenge testing with pharmacological, physical and sensitizing stimuli in adults. Eur Respir J 1993; 6: Suppl. 16, 53-83.

14 Beach J, Russell K, Blitz S, et al. A systematic review of the diagnosis of occupational asthma. Chest 2007; 131: 569-578.

15 Ortega HG, Weissman DN, Carter DL, et al. Use of specific inhalation challenge in the evaluation of workers at risk for occupational asthma: a survey of pulmonary, allergy, and occupational medicine residency training programs in the United States and Canada. Chest 2002; 121: 1323-1328.

16 Barber CM, Naylor S, Bradshaw LM, et al. Approaches to the diagnosis and management of occupational asthma amongst UK respiratory physicians. Respir Med 2007; 101: 1903-1908.

17 Santos MS, Jung H, Peyrovi J, et al. Occupational asthma and work-exacerbated asthma: factors associated with time to diagnostic steps. Chest 2007; 131: 1768-1775.

18 Barber CM, Naylor S, Bradshaw L, et al. Facilities for investigating occupational asthma in UK non-specialist respiratory departments. Occup Med (Lond) 2008; 58: 71-73.

19 Suojalehto H, Cullinan P. Specific inhalation challenge tests for occupational asthma in Europe: a survey. Eur Respir Rev 2014; [in press, DOI: 10.1183/09059180.00000414].

20 Balmes J, Becklake M, Blanc P, et al. American Thoracic Society Statement: occupational contribution to the burden of airway disease. Am J Respir Crit Care Med 2003; 167: 787-797.

21 Toren K, Blanc PD. Asthma caused by occupational exposures is common - a systematic analysis of estimates of the population-attributable fraction. BMC Pulm Med 2009; 9: 7.

22 Henneberger PK, Redlich CA, Callahan DB, et al. An official American Thoracic Society statement: workexacerbated asthma. Am J Respir Crit Care Med 2011; 184: 368-378. 
Tarlo SM, Leung K, Broder I, et al. Asthmatic subjects symptomatically worse at work: prevalence and characterization among a general asthma clinic population. Chest 2000; 118: 1309-1314.

24 Vandenplas O, Toren K, Blanc PD. Health and socioeconomic impact of work-related asthma. Eur Respir J 2003; 22: 689-697.

25 Vandenplas O, Dressel H, Nowak D, et al. What is the optimal management option for occupational asthma? Eur Respir Rev 2012; 21: 97-104.

26 Crapo RO, Casaburi R, Coates AL, et al. Guidelines for methacholine and exercise challenge testing - 1999. Am J Respir Crit Care Med 2000; 161: 309-329.

27 Bateman ED, Hurd SS, Barnes PJ, et al. Global strategy for asthma management and prevention: GINA executive summary. Eur Respir J 2008; 31: 143-178.

28 Simons FE, Ardusso LR, Bilo MB, et al. 2012 Update: World Allergy Organization Guidelines for the assessment and management of anaphylaxis. Curr Opin Allergy Clin Immunol 2012; 12: 389-399.

29 Cloutier Y, Malo JL. Update on an exposure system for particles in the diagnosis of occupational asthma. Eur Respir J 1992; 5: 887-890.

30 Vandenplas O, Malo JL, Cartier A, et al. Closed-circuit methodology for inhalation challenge tests with isocyanates. Am Rev Respir Dis 1992; 145: 582-587.

31 Fabries JF, Choudat D, Wrobel R, et al. Computerized equipment for the delivery of inhaled doses of solid particles in specific bronchial challenge. J Aerosol Med 2000; 13: 1-10.

32 Caron S, Boileau JC, Malo JL, et al. New methodology for specific inhalation challenges with occupational agents. Respir Res 2010; 11: 72.

33 Melillo G, Bonini S, Cocco G, et al. EAACI provocation tests with allergens. Report prepared by the European Academy of Allergology and Clinical Immunology Subcommittee on provocation tests with allergens. Allergy 1997; 52: $1-35$.

34 Pepys J, Davies RJ, Breslin AB, et al. The effects of inhaled beclomethasone dipropionate (Becotide) and sodium cromoglycate on asthmatic reactions to provocation tests. Clin Allergy 1974; 4: 13-24.

35 Martin GL, Atkins PC, Dunsky EH, et al. Effects of theophylline, terbutaline, and prednisone on antigen-induced bronchospasm and mediator release. J Allergy Clin Immunol 1980; 66: 204-212.

36 Burge PS, Efthimiou J, Turner-Warwick M, et al. Double-blind trials of inhaled beclomethasone diproprionate and fluocortin butyl ester in allergen-induced immediate and late asthmatic reactions. Clin Allergy 1982; 12: 523-531.

37 Fabbri LM, Chiesura-Corona P, Dal Vecchio L, et al. Prednisone inhibits late asthmatic reactions and the associated increase in airway responsiveness induced by toluene-diisocyanate in sensitized subjects. Am Rev Respir Dis 1985; 132: 1010-1014.

38 Boschetto P, Fabbri LM, Zocca E, et al. Prednisone inhibits late asthmatic reactions and airway inflammation induced by toluene diisocyanate in sensitized subjects. J Allergy Clin Immunol 1987; 80: 261-267.

39 Cockcroft DW, Murdock KY. Comparative effects of inhaled salbutamol, sodium cromoglycate, and beclomethasone dipropionate on allergen-induced early asthmatic responses, late asthmatic responses, and increased bronchial responsiveness to histamine. J Allergy Clin Immunol 1987; 79: 734-740.

40 Mapp C, Boschetto P, dal Vecchio L, et al. Protective effect of antiasthma drugs on late asthmatic reactions and increased airway responsiveness induced by toluene diisocyanate in sensitized subjects. Am Rev Respir Dis 1987; 136: 1403-1407.

41 De Marzo N, Fabbri LM, Crescioli S, et al. Dose-dependent inhibitory effect of inhaled beclomethasone on late asthmatic reactions and increased responsiveness to methacholine induced by toluene diisocyanate in sensitised subjects. Pulm Pharmacol 1988; 1: 15-20.

42 Cockcroft DW, McParland CP, O’Byrne PM, et al. Beclomethasone given after the early asthmatic response inhibits the late response and the increased methacholine responsiveness and cromolyn does not. J Allergy Clin Immunol 1993; 91: 1163-1168.

43 Paggiaro PL, Dente FL, Morelli MC, et al. Postallergen inhaled budesonide reduces late asthmatic response and inhibits the associated increase of airway responsiveness to methacholine in asthmatics. Am J Respir Crit Care Med 1994; 149: 1447-1451.

44 Gauvreau GM, Doctor J, Watson RM, et al. Effects of inhaled budesonide on allergen-induced airway responses and airway inflammation. Am J Respir Crit Care Med 1996; 154: 1267-1271.

45 Wood LJ, Sehmi R, Gauvreau GM, et al. An inhaled corticosteroid, budesonide, reduces baseline but not allergeninduced increases in bone marrow inflammatory cell progenitors in asthmatic subjects. Am J Respir Crit Care Med 1999; 159: 1457-1463.

46 Kelly EA, Busse WW, Jarjour NN. Inhaled budesonide decreases airway inflammatory response to allergen. Am J Respir Crit Care Med 2000; 162: 883-890.

47 Inman MD, Watson RM, Rerecich T, et al. Dose-dependent effects of inhaled mometasone furoate on airway function and inflammation after allergen inhalation challenge. Am J Respir Crit Care Med 2001; 164: 569-574

48 Subbarao P, Dorman SC, Rerecich T, et al. Protection by budesonide and fluticasone on allergen-induced airway responses after discontinuation of therapy. J Allergy Clin Immunol 2005; 115: 745-750.

49 D'Alpaos V, Vandenplas O, Evrard G, et al. Inhalation challenges with occupational agents: threshold duration of exposure. Respir Med 2013; 107: 739-744.

50 Stenton SC, Avery AJ, Walters EH, et al. Statistical approaches to the identification of late asthmatic reactions. Eur Respir J 1994; 7: 806-812.

51 Cockcroft DW. Bronchial inhalation tests. II. Measurement of allergic (and occupational) bronchial responsiveness. Ann Allergy 1987; 59: 89-98.

52 Vandenplas O, Cartier A, Lesage J, et al. Occupational asthma caused by a prepolymer but not the monomer of toluene diisocyanate (TDI). J Allergy Clin Immunol 1992; 89: 1183-1188.

53 Vandenplas O, Cartier A, Lesage J, et al. Prepolymers of hexamethylene diisocyanate as a cause of occupational asthma. J Allergy Clin Immunol 1993; 91: 850-861.

54 Lemière C, Desjardins A, Cloutier Y, et al. Occupational asthma due to formaldehyde resin dust with and without reaction to formaldehyde gas. Eur Respir J 1995; 8: 861-865.

55 Tatham AS, Shewry PR. Allergens to wheat and related cereals. Clin Exp Allergy 2008; 38: $1712-1726$. 
56 van Kampen V, Merget R, Rabstein S, et al. Comparison of wheat and rye flour solutions for skin prick testing: a multi-centre study (Stad 1). Clin Exp Allergy 2009; 39: 1896-1902.

57 Vandenplas O, D’Alpaos V, Evrard G, et al. Incidence of severe asthmatic reactions after challenge exposure to occupational agents. Chest 2013; 143: 1261-1268.

58 Perrin B, Cartier A, Ghezzo H, et al. Reassessment of the temporal patterns of bronchial obstruction after exposure to occupational sensitizing agents. J Allergy Clin Immunol 1991; 87: 630-639.

59 Vandenplas $\mathrm{O}$, Cartier A, Ghezzo H, et al. Response to isocyanates: effect of concentration, duration of exposure, and dose. Am Rev Respir Dis 1993; 147: 1287-1290.

60 Nguyen B, Weytjens K, Cloutier Y, et al. Determinants of the bronchial response to high molecular weight occupational agents in a dry aerosol form. Eur Respir J 1998; 12: 885-888.

61 Cockcroft DW, Murdock KY, Kirby J, et al. Prediction of airway responsiveness to allergen from skin sensitivity to allergen and airway responsiveness to histamine. Am Rev Respir Dis 1987; 135: $264-267$.

62 Cockcroft DW, Davis BE, Boulet LP, et al. The links between allergen skin test sensitivity, airway responsiveness and airway response to allergen. Allergy 2005; 60: 56-59.

63 Barnig C, Purohit A, Casset A, et al. Nonallergic airway hyperresponsiveness and allergen-specific IgE levels are the main determinants of the early and late asthmatic response to allergen. J Investig Allergol Clin Immunol 2013; 23: 267-274.

64 Quirce S, Fernandez-Nieto M, Escudero C, et al. Bronchial responsiveness to bakery-derived allergens is strongly dependent on specific skin sensitivity. Allergy 2006; 61: 1202-1208.

65 Cockcroft DW, Berscheid BA. Measurement of responsiveness to inhaled histamine: comparison of FEV1 and SGaw. Ann Allergy 1983; 51: 374-377.

66 Vandenplas O, Caroyer JM, Cangh FB, et al. Occupational asthma caused by a natural food colorant derived from Monascus ruber. J Allergy Clin Immunol 2000; 105: 1241-1242.

67 Vandenplas O, D’Alpaos V, Cesar M, et al. Occupational asthma caused by linseed oilcake. Allergy 2008; 63: $1250-1251$.

68 Quanjer PH, Tammeling GJ, Cotes JE, et al. Lung volumes and forced ventilatory flows. Eur Respir J 1993; 6: Suppl. $16,5-40$.

69 Miller MR, Hankinson J, Brusasco V, et al. Standardisation of spirometry. Eur Respir J 2005; 26: 319-338.

70 Weytjens K, Malo JL, Cartier A, et al. Comparison of peak expiratory flows and FEV1 in assessing immediate asthmatic reactions due to occupational agents. Allergy 1999; 54: 621-625.

71 Moore VC, Parsons NR, Jaakkola MS, et al. Serial lung function variability using four portable logging meters. J Asthma 2009; 46: 961-966.

72 Fish JE, Kelly JF. Measurements of responsiveness in bronchoprovocation testing. J Allergy Clin Immunol 1979; 64: 592-596.

73 Dehaut P, Rachiele A, Martin RR, et al. Histamine dose-response curves in asthma: reproducibility and sensitivity of different indices to assess response. Thorax 1983; 38: 516-522.

74 Frolund L, Madsen F, Svendsen UG, et al. Reproducibility of responsiveness to a standardized bronchial allergen provocation-Rt compared to FEV1 as measurement of response to provocation. Clin Allergy 1987; 17: 217-228.

75 Oostveen E, MacLeod D, Lorino $\mathrm{H}$, et al. The forced oscillation technique in clinical practice: methodology, recommendations and future developments. Eur Respir J 2003; 22: 1026-1041.

76 Larbanois A, Delwiche JP, Jamart J, et al. Comparison of FEV1 and specific airway conductance in assessing airway response to occupational agents. Allergy 2003; 58: 1256-1260.

77 Malo J, Ghezzo H, L'Archeveque J. Distinct temporal patterns of immediate asthmatic reactions due to high- and low-molecular-weight agents. Clin Exp Allergy 2012; 42: 1021-1027.

78 Malo JL. "Daily pattern" of an asthmatic reaction due to isocyanates. Allergy 2004; 59: 234-235.

79 Vandenplas O, Delwiche JP, Jamart J, et al. Increase in non-specific bronchial hyperresponsiveness as an early marker of bronchial response to occupational agents during specific inhalation challenges. Thorax 1996; 51: 472-478.

80 Sastre J, Fernandez-Nieto M, Novalbos A, et al. Need for monitoring nonspecific bronchial hyperresponsiveness before and after isocyanate inhalation challenge. Chest 2003; 123: 1276-1279.

81 Vandenplas O, D'Alpaos V, Heymans J, et al. Sputum eosinophilia: an early marker of bronchial response to occupational agents. Allergy 2009; 64: 754-761.

82 Leigh R, Hargreave FE. Occupational neutrophilic asthma. Can Respir J 1999; 6: 194-196.

83 Lemière $\mathrm{C}$, Romeo $\mathrm{P}$, Chaboillez $\mathrm{S}$, et al. Airway inflammation and functional changes after exposure to different concentrations of isocyanates. J Allergy Clin Immunol 2002; 110: 641-646.

84 Pala G, Pignatti P, Moscato G. Occupational exposure to toluene diisocyanate and neutrophilic bronchitis without asthma. Clin Toxicol (Phila) 2011; 49: 506-507.

85 Quirce S, Lemiere C, de Blay F, et al. Noninvasive methods for assessment of airway inflammation in occupational settings. Allergy 2010; 65: 445-459.

86 Pala G, Pignatti P, Moscato G. The use of fractional exhaled nitric oxide in investigation of work-related cough in a hairdresser. Am J Ind Med 2011; 54: 565-568.

87 Obata H, Dittrick M, Chan H, et al. Sputum eosinophils and exhaled nitric oxide during late asthmatic reaction in patients with western red cedar asthma. Eur Respir J 1999; 13: 489-495.

88 Piipari R, Piirila P, Keskinen H, et al. Exhaled nitric oxide in specific challenge tests to assess occupational asthma. Eur Respir J 2002; 20: 1532-1537.

89 Baur X, Barbinova L. Latex allergen exposure increases exhaled nitric oxide in symptomatic healthcare workers. Eur Respir J 2005; 25: 309-316.

90 Barbinova L, Baur X. Increase in exhaled nitric oxide (eNO) after work-related isocyanate exposure. Int Arch Occup Environ Health, 2006: 1-9.

91 Swierczynska-Machura D, Krakowiak A, Wiszniewska M, et al. Exhaled nitric oxide levels after specific inahalatory challenge test in subjects with diagnosed occupational asthma. Int J Occup Med Environ Health 2008; 21: 219-225.

92 Ferrazzoni S, Scarpa MC, Guarnieri G, et al. Exhaled nitric oxide and breath condensate $\mathrm{pH}$ in asthmatic reactions induced by isocyanates. Chest 2009; 136: 155-162. 
93 Pedrosa M, Barranco P, Lopez-Carrasco V, et al. Changes in exhaled nitric oxide levels after bronchial allergen challenge. Lung 2012; 190: 209-214.

94 Sastre J, Costa C, del García Potro M, et al. Changes in exhaled nitric oxide after inhalation challenge with occupational agents. J Invest Allergol Clin Immunol 2013; 23: 421-427.

95 Walters GI, Moore V, Mc Grath EE, et al. Fractional exhaled nitric oxide in the interpretation of specific inhalational challenge tests for occupational asthma. Lung 2013 [in press, DOI: 10.1007/s00408-013-9531-z].

96 Lemiere C, D'Alpaos V, Chaboillez S, et al. Investigation of occupational asthma: sputum cell counts or exhaled nitric oxide? Chest 2010; 137: 617-622.

97 Hendrick DJ, Marshall R, Faux JA, et al. Positive "alveolar" responses to antigen inhalation provocation tests: their validity and recognition. Thorax 1980; 35: 415-427.

98 Ramirez-Venegas A, Sansores RH, Perez-Padilla R, et al. Utility of a provocation test for diagnosis of chronic pigeon breeder's disease. Am J Respir Crit Care Med 1998; 158: 862-869.

99 Morell F, Roger A, Reyes L, et al. Bird fancier's lung: a series of 86 patients. Medicine 2008; 87: 110-130.

100 Castano R, Theriault G, Gautrin D, et al. Reproducibility of acoustic rhinometry in the investigation of occupational rhinitis. Am J Rhinol 2007; 21: 474-477.

101 Moscato G, Vandenplas O, Gerth Van Wijk R, et al. Occupational rhinitis. Allergy 2008; 63: 969-980.

102 Pignatti P, Pala G, Pisati M, et al. Nasal blown secretion evaluation in specific occupational nasal challenges. Int Arch Occup Environ Health 2009; 83: 217-223.

103 Moscato G, Pala G, Perfetti L, et al. Clinical and inflammatory features of occupational asthma caused by persulphate salts in comparison with asthma associated with occupational rhinitis. Allergy 2010; 65: 784-790.

104 Moore VC, Jaakkola MS, Burge CB, et al. A new diagnostic score for occupational asthma: the area between the curves (ABC score) of peak expiratory flow on days at and away from work. Chest 2009; 135: 307-314.

105 Burge CB, Moore VC, Pantin CF, et al. Diagnosis of occupational asthma from time point differences in serial PEF measurements. Thorax 2009; 64: 1032-1036.

106 Anees W, Blainey D, Moore VC, et al. Differentiating occupational asthmatics from non-occupational asthmatics and irritant-exposed workers. Occup Med (Lond) 2011; 61: 190-195.

107 Baur X, Huber H, Degens PO, et al. Relation between occupational asthma case history, bronchial methacholine challenge, and specific challenge test in patients with suspected occupational asthma. Am J Ind Med 1998; 33: $114-122$.

108 Dweik RA, Boggs PB, Erzurum SC, et al. An official ATS clinical practice guideline: interpretation of exhaled nitric oxide levels (FENO) for clinical applications. Am J Respir Crit Care Med 2011; 184: 602-615.

109 Barranco P, Fernandez-Nieto M, del Pozo V, et al. Nonasthmatic eosinophilic bronchitis in a baker caused by fungal alpha-amylase and wheat flour. J Investig Allergol Clin Immunol 2008; 18: 494-495.

110 Di Stefano F, Di Giampaolo L, Verna N, et al. Occupational eosinophilic bronchitis in a foundry worker exposed to isocyanate and a baker exposed to flour. Thorax 2007; 62: 368-370.

111 Yacoub MR, Malo JL, Labrecque M, et al. Occupational eosinophilic bronchitis. Allergy 2005; 60: 1542-1544.

112 Krakowiak AM, Dudek W, Ruta U, et al. Occupational eosinophilic bronchitis without asthma due to chloramine exposure. Occup Med (Lond) 2005; 55: 396-368.

113 Quirce S. Eosinophilic bronchitis in the workplace. Curr Opin Allergy Clin Immunol 2004; 4: 87-91.

114 Quirce S, Fernandez-Nieto M, de Miguel J, et al. Chronic cough due to latex-induced eosinophilic bronchitis. J Allergy Clin Immunol 2001; 108: 143.

115 Ogawa H, Fujimura M, Heki U, et al. Eosinophilic bronchitis presenting with only severe dry cough due to bucillamine. Respir Med 1995; 89: 219-221.

116 Malo JL, Ghezzo H, L'Archevêque J, et al. Late asthmatic reactions to occupational sensitizing agents: frequency of changes in nonspecific bronchial responsiveness and of response to inhaled $\beta 2$-adrenergic agent. J Allergy Clin Immunol 1990; 85: 834-842.

117 Dufour MH, Lemiere C, Prince P, et al. Comparative airway response to high- versus low-molecular weight agents in occupational asthma. Eur Respir J 2009; 33: 734-739.

118 Mapp CE, Corona PC, De Marzo N, et al. Persistent asthma due to isocyanates. A follow-up study of subjects with occupational asthma due to toluene diisocyanate (TDI). Am Rev Respir Dis 1988; 137: 1326-1329.

119 Paggiaro PL, Vagaggini B, Dente FL, et al. Bronchial hyperresponsiveness and toluene diisocyanate. Long-term change in sensitized asthmatic subjects. Chest 1993; 103: 1123-1128.

120 Pisati G, Baruffini A, Bernabeo F, et al. Rechallenging subjects with occupational asthma due to toluene diisocyanate (TDI), after long-term removal from exposure. Int Arch Occup Environ Health 2007; 80: 298-305.

121 Merget R, Reineke M, Rueckmann A, et al. Nonspecific and specific bronchial responsiveness in occupational asthma caused by platinum salts after allergen avoidance. Am J Respir Crit Care Med 1994; 150: 1146-1149.

122 Lemière C, Cartier A, Dolovich J, et al. Outcome of specific bronchial responsiveness to occupational agents after removal from exposure. Am J Respir Crit Care Med 1996; 154: 329-333.

123 Lemière C, Cartier A, Malo JL, et al. Persistent specific bronchial reactivity to occupational agents in workers with normal nonspecific bronchial reactivity. Am J Respir Crit Care Med 2000; 162: 976-980.

124 Bernstein IL, Chan-Yeung M, Malo JL, et al. Definition and classification of asthma in the workplace. In: Bernstein IL, Chan-Yeung M, Malo JL, et al, eds. Asthma in the Workplace. 3rd Edn. New York, Marcel Dekker Inc., 2006; pp. $1-8$.

125 Harving H, Korsgaard J, Dahl R, et al. Low concentrations of formaldehyde in bronchial asthma: a study of exposure under controlled conditions. Br Med J 1986; 293: 310.

126 Green DJ, Sauder LR, Kulle TJ, et al. Acute response to $3.0 \mathrm{ppm}$ formaldehyde in exercising healthy nonsmokers and asthmatics. Am Rev Respir Dis 1987; 135: 1261-1266.

127 De Luca S, Caire N, Cloutier Y, et al. Acute exposure to sawdust does not alter airway calibre and responsiveness to histamine in asthmatic subjects. Eur Respir J 1988; 1: 540-546.

128 Harving H, Dahl R, Molhave L. Lung function and bronchial reactivity in asthmatics during exposure to volatile organic compounds. Am Rev Respir Dis 1991; 143: 751-754.

129 Beach JR, Raven J, Ingram C, et al. The effects on asthmatics of exposure to a conventional water-based and a volatile organic compound-free paint. Eur Respir J 1997; 10: 563-566. 
130 Vandenplas O, Delwiche JP, Staquet P, et al. Pulmonary effects of short-term exposure to low levels of toluene diisocyanate in asymptomatic subjects. Eur Respir J 1999; 13: 1144-1150.

131 Trenga CA, Koenig JQ, Williams PV. Sulphur dioxide sensitivity and plasma antioxidants in adult subjects with asthma. Occup Environ Med 1999; 56: 544-547.

132 D'Alessandro A, Kuschner W, Wong H, et al. Exaggerated responses to chlorine inhalation among persons with nonspecific airway hyperreactivity. Chest 1996; 109: 331-337.

133 Sastre J, Madero MF, Fernandez-Nieto M, et al. Airway response to chlorine inhalation (bleach) among cleaning workers with and without bronchial hyperresponsiveness. Am J Ind Med 2011; 54: 293-299.

134 Cockcroft DW, Hoeppner VH, Werner GD. Recurrent nocturnal asthma after bronchoprovocation with Western Red Cedar sawdust: association with acute increase in non-allergic bronchial responsiveness. Clin Allergy 1984; 14: 61-68.

135 Lemiere C, Gautrin D, Trudeau C, et al. Fever and leukocytosis accompanying asthmatic reactions due to occupational agents: frequency and associated factors. Eur Respir J 1996; 9: 517-523.

136 Kaplan I, Zeligman I. Urticaria and asthma from acetylene welding. Arch Dermatol 1963; 88: $188-189$.

137 Moller DR, Brooks SM, Bernstein DI, et al. Delayed anaphylactoid reaction in a worker exposed to chromium. J Allergy Clin Immunol 1986; 77: 451-456.

138 Romano C, Sulotto F, Pavan I, et al. A new case of occupational asthma from reactive dyes with severe anaphylactic response to the specific challenge. Am J Ind Med 1992; 21: 209-216.

139 Hannu T, Alanko K, Keskinen H. Anaphylaxis and allergic contact urticaria from occupational airborne exposure to HBTU. Occup Med (Lond) 2006; 56: 430-433.

140 Krecisz B, Kiec-Swierczynska M, Krawczyk P, et al. Cobalt-induced anaphylaxis, contact urticaria, and delayed allergy in a ceramics decorator. Contact Dermatitis 2009; 60: 173-174.

141 Kennedy WA, Girard F, Chaboillez S, et al. Cost-effectiveness of various diagnostic approaches for occupational asthma. Can Respir J 2007; 14: 276-280. 